\title{
Spinal mechanical load: a predictor of persistent low back pain? A prospective cohort study
}

\author{
Eric W. P. Bakker · Arianne P. Verhagen • \\ Cees Lucas · Hans J. C. M. F. Koning · Bart W. Koes
}

Received: 22 August 2006/Revised: 22 December 2006/Accepted: 25 February 2007/Published online: 12 April 2007

(C) Springer-Verlag 2007

\begin{abstract}
Prospective inception cohort. To assess the prognostic value of spinal mechanical load, assessed with the 24-hour schedule (24HS), in subjects with acute nonspecific low back pain (ALBP) and to examine the influence of spinal mechanical load on the course of ALBP. In view of the characteristics of the natural course of ALBP, this should be viewed as a persistent condition in many patients rather that a benign self-limiting disease. Therefore, secondary prevention could be beneficial. Spinal mechanical load is a risk factor for ALBP and possibly a (modifiable) prognostic factor for persistent (i.e. recurrent and/or chronic) LBP. One hundred patients from primary care with ALBP were eligible for inclusion. At 6 months, 88 subjects completed the follow-up. For the follow-up assessment a research assistant, unaware of our interest in the prognostic factors, contacted the subjects by telephone. Questionnaires were completed focusing on changes in demographic data and on the course and current status of ALBP. Persistent LBP occurred in $60 \%$ subjects. After multivariate regression analysis smoking (harmful) and advanced age (protective) were associated with persistent LBP. Differences in 24HS scores at baseline and follow-up were univariate-related to persistent LBP. Spinal mechanical load, quantified
\end{abstract}

E. W. P. Bakker $(\bowtie) \cdot$ A. P. Verhagen · B. W. Koes Department of General Practice, Erasmus University Rotterdam, P.O. Box 1738, 3000 DR Rotterdam, The Netherlands e-mail: ewp.bakker@zonnet.nl

\section{Lucas}

Department of Clinical Epidemiology and Biostatistics, Amsterdam Medical Centre, Amsterdam, The Netherlands

H. J. C. M. F. Koning

Physiotherapy Centre, Prins Hendrikstraat 184,

2518 HZ The Hague, The Netherlands with the 24HS, is not a prognostic factor for persistent LBP. Modification of spinal mechanical load in terms of 24HS scores could be beneficial for secondary prevention in patients with acute LBP.

Keywords Cohort · Follow-up - Low back pain · Prognosis $\cdot$ Mechanical load $\cdot$ 24-hour schedule

\section{Introduction}

Low back pain (LBP) is a common condition. On any given day $12-33 \%$ of the people report some back pain [31]. It was suggested that acute LBP is a benign self-limiting disease with a recovery rate of $80-90 \%$ within 6 weeks irrespective of the management or type of treatment [29], but a recent systematic review did not find any evidence for this [19]. In view of the characteristics of the natural course, acute LBP should be viewed as a persistent condition in many patients [6]. In 1998, the direct costs of back pain were $0.19 \%$ and indirect cost between 0.12 and $0.58 \%$ of the United Kingdoms' Gross Domestic Product [15]. Secondary prevention, i.e. prevention of recurrent episodes, might be beneficial in the management of LBP. For secondary prevention, knowledge of the prognostic factors is essential. In the literature, prognostic factors for persistent LBP vary from measures of LBP itself, psychological indicators to socio-demographic factors [8]. In a previous study, spinal mechanical load quantified with the 24-hour schedule (24HS), was independently associated with the occurrence of acute non-specific LBP. Consequently, spinal mechanical load was regarded as a risk factor for LBP [4].

The 24HS is a one-dimensional questionnaire developed for quantifying spinal mechanical load (posture and spinal 
load applied) in the subject at issue. The 24HS has face, content and construct validity and the inter-observer reliability was shown to be high $[3,4]$.

The purpose of this prospective study was to assess the prognostic value of spinal mechanical load, quantified with the 24HS, for predicting persistent (i.e. recurrent and/or chronic) LBP in subjects with acute LBP, and to examine the influence of changes in spinal mechanical load, quantified with the 24HS, on the course of LBP.

\section{Methods}

\section{Study population}

An inception cohort was formed of subjects diagnosed with acute (i.e. an episode of LBP lasting less than 6 weeks) non-specific LBP [11]. Forty general practitioners (GP) in the city of The Hague, The Netherlands were asked to refer patients with LBP to one of the assessors in one of the four local research centres. Non-specific LBP was applicable if the anamnesis and physical examination ruled out specific pathologic ('red flag' conditions such as tumour, infection, or fracture), and sciatica/radicular syndrome. The physical examination includes localisation of the pain, the assessment of spinal movements, and Straight Leg Raising test $[5,10]$. Patients were eligible for inclusion if an assessor confirmed the 'diagnosis' LBP. Exclusion criteria were: insufficient understanding of the Dutch language, previous episode(s) of LBP in the past 12 months, LBP after a significant trauma, pregnancy, spinal surgery, and known pathology suspicious of specific LBP. Definitions used in this study are in accordance with the Dutch Guideline for General Practitioners 'Low Back Pain' and internationally accepted $[5,10]$.

\section{Baseline assessment}

All 18 assessors were physiotherapists. All subjects signed informed consent and were coded for anonymity. Questionnaires were completed focusing on subjects' demographic data and the following known prognostic factors: factors related to the episode of LBP: pain intensity at consultation [26], duration of symptoms (maximum 6 weeks), radiating leg pain (below the knee) [27], and restricted spinal movement [25]. The following prognostic factors present before the onset of the episode LBP were also listed: gender, age [7], previous episode(s) of LBP (longer than 12 months ago) [26], and smoking [27]. Social and psychological factors [20, 21] were measured with the Nottingham Health Profile-Dutch Version-(NHP) [9] and the Acute Low Back Pain Screening Questionnaire, Dutch version (ALBSQ) [28].
(Un-) employment [27] and job satisfaction [18] were assessed separately.

Radiating leg pain, smoking, and unemployment were dichotomised as: YES if subjects indicated to experience the prognostic factor and NO if subjects indicated not to experience the prognostic factor. Pain intensity at consultation, job satisfaction, and restricted spinal movement were measured with an 11-point Numeric Rating Scale, where ' 0 ' indicates a minimum or poor and ' 10 ' a maximum or good score [13]. The scores of the six domains of the NHP I and II were summed and presented as mean score (ranging 0-87). Finally, the 24HS was used for the assessment of spinal mechanical loading.

The procedure of the $24 \mathrm{HS}$ measurement

An assessor, trained in using the 24HS, systematically asked the subjects to describe their daily activities. Of each activity, the position of the back in the sagittal plane (i.e. flexed or extended), the load applied and the duration, were listed chronologically on the standardised registration form (see Addendum the 24HS registration form). For 'load applied', the following three categories were available: (1) no load applied (e.g. lying), (2) loaded (e.g. sitting) and (3) loaded with movement (e.g. digging). After completing the registration, subject's flexed-posture score was calculated first. Of each activity, the duration was multiplied by the weight of the category the activity was scored in and all obtained scores were added up. The weight of the categories, based on Nachemsons' findings modified by Sato [16, 24], was set to 1:2:3 [3]. For example, an activity scored $5 \mathrm{~h}$ in the second category on the registration form, becomes $10 \mathrm{~h}$ when recalculated to the first category. An activity scored $5 \mathrm{~h}$ in the third category will be recalculated to $15 \mathrm{~h}$ in the first category. The resulting figure represents the time the back was loaded in a flexed posture with a load of the first category. The parameter we called schedule hours, ranges from 0 to 72 . Subsequently, this procedure was repeated for the extended posture (range 0-72). The sum-score was obtained by subtracting the total time of the extended postures from the total time of the flexed postures. The resulting figure gives insight into the dominant use (the training activity) of the back (range -72 to +72 schedule hours). Negative sum-scores point to an overall spine use in extended and positive sum-scores indicates an overall spine use in flexed postures.

After baseline measurement, all subjects received guideline-based information [5, 10], including reassuring the patient of a favourable prognosis, encouraging the patient to stay active and discouraging bed rest [14]. Finally, the outcome of the assessment was explained. All information was summarised in a brochure, which patients received. The total time required for the assessment was 


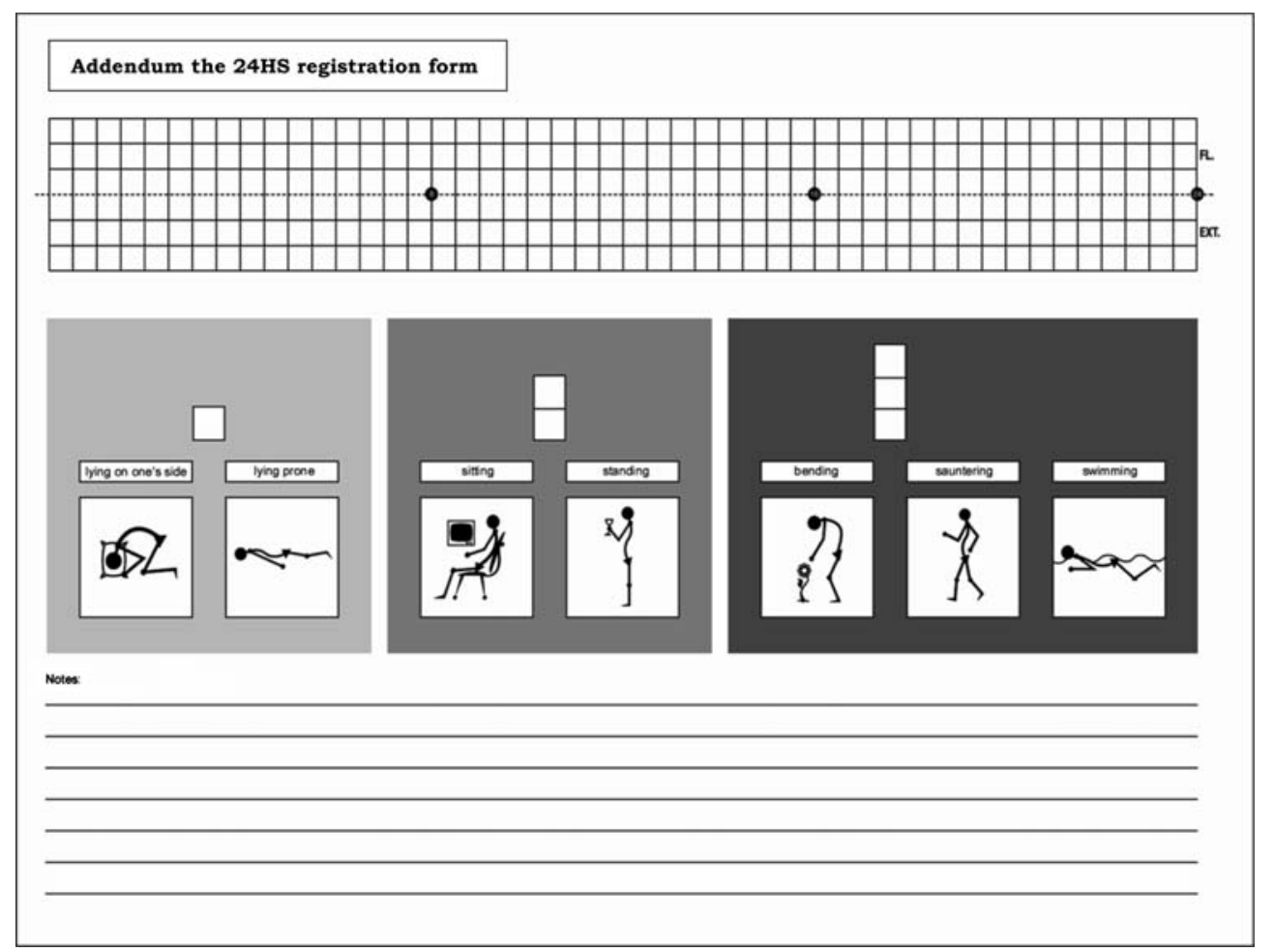

$30 \mathrm{~min}$; including $10 \mathrm{~min}$ for guideline-based information, explanation and summarising.

\section{Follow-up}

After 6 months, a research assistant contacted subjects by telephone. This research assistant was trained in the assessment of the 24HS, but not how to interpret it. Furthermore, the assistant was unaware of our special interest in the prognostic factors assessed. In this manner we tried to achieve an objective, unbiased measurement. During this interview the subjects answered questions focusing on changes in the subjects' demographical data as work or daily occupation and possible pregnancy, the characteristics of the initial episode LBP (duration of the complaints, care seeking including receiving physical therapy [12]), and (if relevant) the characteristics of the recurrence episode(s). Finally, the subjects were asked for their opinion of the received 'hands-off', strategy for LBP, as advised in the Guideline for General Practitioners 'Low Back Pain' $[5,10]$. Subjects' opinion was measured with an 11-point Numeric Rating Scale ${ }^{13}$. The 24HS was assessed in order to quantify changes in spinal mechanical loading compared to the baseline measurement.

In this study, the primary dependent variable was persistent LBP. Persistent LBP was applicable if a subject experienced a recurrence episode(s) and/or subjects' episode of LBP was labelled chronic, i.e. subjects' episode lasted longer than 12 weeks [8]. Persistent LBP was dichotomised and was regarded positive if the subject did experience a recurrent episode and/or subject s' episode of LBP lasted longer than 12 weeks. If the subject did not experience a recurrent episode or subject s' episode of LBP did not last longer than 12 weeks, the variable persistent LBP was scored as NO. To determine if a subject had persistent LBP or not, the variables recurrence episode(s) and chronicity were separately assessed. These variables were also dichotomised; YES, if subject did experience a recurrent episode or subjects' episode LBP lasted longer than 12 weeks. NO, if subject did not experience a recurrent episode or subjects' episode LBP did not last longer than 12 weeks. The independent variables were the following prognostic factors: the 24HS-sum-scores, gender, age, previous episode(s) of LBP, smoking, NHP, ALBSQ, (un-) employment, job satisfaction, pain intensity at consultation, duration of symptoms of the baseline episode LBP, radiating leg pain, restricted spinal movement, and receiving physical therapy.

\section{Sample size}

The odds ratio (OR) was used to express the association between the dependent and the independent variables. For the association between the dependent variables and the mean 24HS sum-scores, an OR of 1.5 was considered clinically relevant. Power analysis indicated that (using an 
alpha of 0.05 and a power of 0.80 and an expected $15 \%$ dropout [1] 100 participants would be sufficient to detect such difference with statistical significance.

\section{Analysis}

A logistic regression analysis was used for calculating the associations between the dependent variables (persistent LBP, recurrence episode(s) or chronicity) and the independent variables. After a univariate regression analysis, a multivariate logistic regression (model Backward Wald) was run on the independent variables that showed a relation to persistent LBP, recurrence episode(s) or chronicity. Threshold for entry of independent variables in the multivariate model was $P<0.05$ and for removal $P>0.1$ [2]. The Nagelkerke $R^{2}$ was used to assess the explained variance of the model.

To assess the association between the dependent variable persistent LBP and the continue predictor changes in 24HS score (i.e. difference in baseline and follow-up 24HS scores), a univariate regression analysis was used.

After the blinded, double data entry, all analyses were carried out in SPSS 11.0. First, frequencies of risk factors are presented with their mean and standard deviation (SD). In case of skewed distributions median and Interquartile Range (IQR) were used. Differences between the group completing the follow-up versus those lost-to-follow-up were compared using the Paired-Samples $T$ Test or, in case of skewed distributions, the non-parametric Mann-Whitney $U$ test.
The Medical Ethics Committee of the Erasmus Medical Centre (Rotterdam, The Netherlands) approved the study.

\section{Results}

Patients

One hundred subjects were eligible for entering the study of which three subjects were excluded. Two had a previous episode LBP in the past 12-months, and one had complaints lasting longer than 6 weeks. A total of 97 subjects were included. The median duration of LBP when included was 1 week (IQR 0-3 weeks). At 6 months, nine subjects dropped out, of which one did not want to participate, and two moved outside the Netherlands. We were not able to contact six subjects, resulting in 88 subjects completing the study. The baseline characteristics of all 97 subjects as well as subjects completing the 6-months follow-up and dropouts are shown in Table 1. The nine dropouts differ statistically significant from the subjects that completed the follow-up in: gender (more women), previous episode(s) (higher prevalence) and ALBPSQ scores (higher). Therefore, it is likely that this group is somewhat more at risk for persistent low back pain.

\section{Baseline LBP}

The median duration of the complaints was four weeks (IQR 2-8). Chronicity of LBP occurred in 12 (14\%) sub-

Table 1 Characteristics of the study population

\begin{tabular}{llll}
\hline Prognostic factors & Baseline $N=97$ & Lost-to-follow-up $N=9$ & Follow-up $N=88$ \\
\hline Male (\%) & $52 / 97(54)$ & $3 / 9(33)$ & $49 / 88(56)$ \\
Age, mean (minimum-maximum, SD) & $40.7(15-82,13.5)$ & $37.4(26-56,9.4)$ & $41(15-82,14)$ \\
Previous episode(s) LBP (\%) & $70 / 97(72)$ & $8 / 9(88)$ & $58 / 88(67)$ \\
Smoking (\%) & $34 / 97(35)$ & $5 / 9(56)$ & $29 / 88(33)$ \\
24HS sum-scores, mean (SD) & $34.4(8.2)$ & $32.5(9.0)$ & $34.6(8.1)$ \\
NHP sum-scores, mean (SD) range 0-87 & $2.88(2.2)$ & $2.7(1.7)$ & $2.87(2.3)$ \\
ALBPSQ, median (IQR). Range 12-192 & $65(42-84)$ & $84(46-94)$ & $64(42-78)$ \\
Unemployment (\%) & $7 / 97(7)$ & $1 / 9(11)$ & $6 / 88(7)$ \\
Job satisfaction, mean (SD) & $7.5(2.5)$ & $7(2.9)$ & $7.6(2.5)$ \\
Pain NRS, median (minimum-maximum) range 0-10 & $6(0-10)$ & $6(0-10)$ & $11.3(6.7)$ \\
Duration of symptoms in days, mean (SD) & $11.7(6.7)$ & $4 / 9(44)$ & $11.8(6.7)$ \\
Pain radiating in one or both legs (\%) & $35 / 97(36)$ & $6.1(3.0)$ & $31 / 88(35)$ \\
Spinal movement, mean (SD) & $6.3(2.2)$ & 5 & $6.5(2.2)$ \\
As for daily occupation or while at work: 'sitting' & 57 & 2 & 52 \\
As for daily occupation or while at work: 'variable work' & 27 & 1 & 25 \\
As for daily occupation or while at work: 'heavy spinal loading' & 7 & 6 & 6 \\
As for daily occupation or while at work: 'other' ('missing') & $3(3)$ & $3(2)$ \\
\hline
\end{tabular}




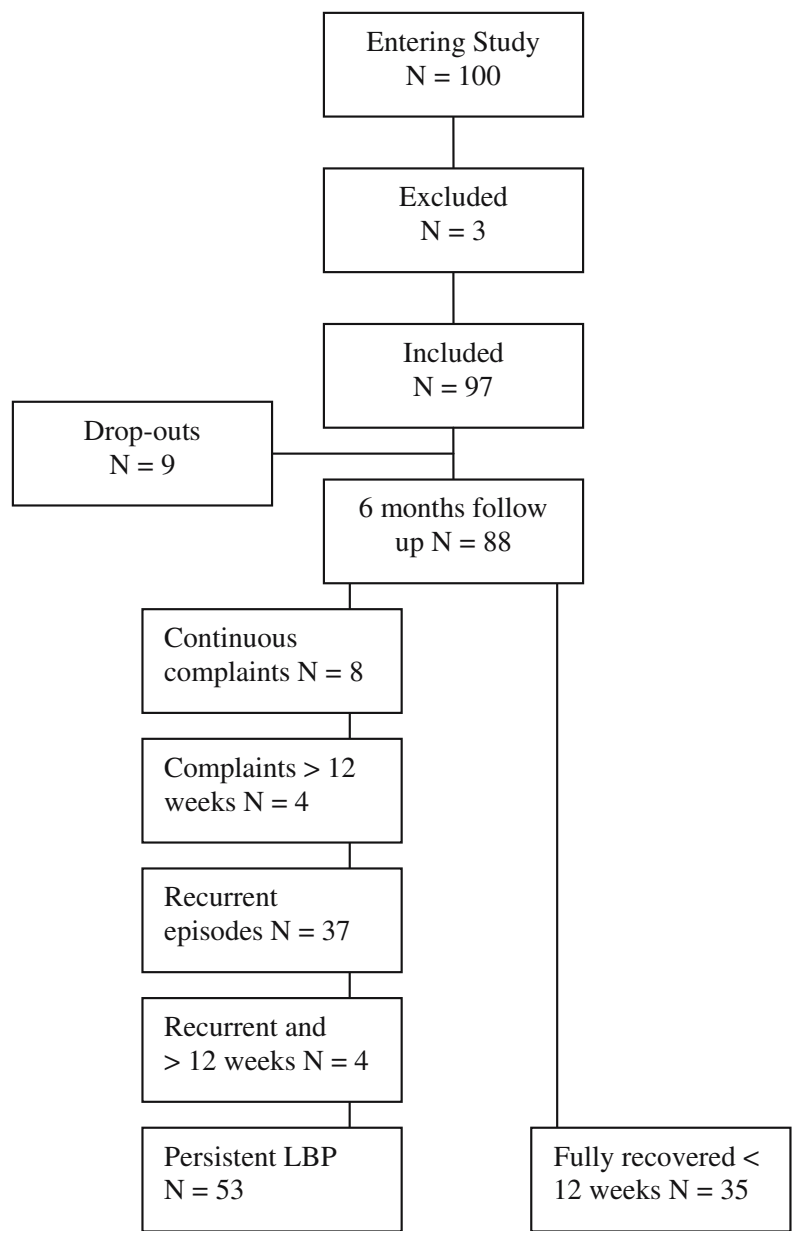

Fig. 1 Flow chart

jects, of whom $8(9 \%)$ had persistent complaints over the 6-month period.

\section{Recurrent LBP}

All recurrent episodes were labelled as non-specific LBP. Pregnancy did not occur in the group who completed the follow-up. In this group, recurrent episode(s) occurred in $37(42 \%)$ subjects and $4(5 \%)$ subjects had recurrent episode(s) lasting longer then 12 weeks (chronic). The median number of recurrent episode(s) was 1 (IQR 0-3). Thirtyfive subjects $(40 \%)$ reported no further complaints after the baseline LBP episode. As a result, the proportion persistent LBP in the group who completed the follow-up was $60 \%$ (see flow chart) Fig. 1.

Changes in demographical data

A total of eight people ( $9 \%$ ) changed work or daily occupation during the follow-up period, of which four $(5 \%)$ became unemployed. Including the five subjects who were unemployed at baseline, the proportion of (un-) employed in the follow-up group was nine (10\%).

Subjects' care seeking for baseline and recurrent LBP are shown in Table 2 .

The total number of GP-consultations reported in this study was 109 , including the index consult. The proportion of GP-consultations per person was 1.2 (109/88). Eighteen (21\%) subjects received physical therapy (unspecified) for baseline LBP or recurrent episodes. Subjects were highly satisfied with the 'hands-off' strategy for LBP (10 IQR 8-10) received.

Prognostic factors for persistent low back pain

First, a univariate regression analysis was performed on persistent LBP as dependent variable and the 14 (previously mentioned) potentially relevant independent variables. Of these, the 24HS sum-scores, smoking and age were univariate significantly related to persistent LBP. After a multivariate regression analysis, age and smoking remained significantly associated with the outcome. The OR for the dichotomised variable smoking was 4.4. The OR for persistent LBP increased by a factor 0.96 for every additional year of age. The explained variance of this model was $16.9 \%$ (Nagelkerke $R^{2}$ ).

This procedure was repeated for recurrent LBP as dependent variable. Here only 24HS sum-scores and age were univariate significantly related to the outcome. After a multivariate regression analysis, age remained significantly associated with recurrent LBP. In the third univariate regression analysis only receiving physical therapy was

Table 2 Subjects' care seeking for baseline and recurrent LBP

\begin{tabular}{|c|c|c|}
\hline & Baseline LBP $N=88$ & Recurrent $\mathrm{LBP}^{\mathrm{a}} N=41$ \\
\hline Consultation GP & Once $7(8 \%)$, twice $3(3 \%)$ & Once $8(20 \%)$ \\
\hline Referral or treatment GP & $\begin{array}{l}\text { Neurology } 1(1 \%) \text {, orthopaedic } 2(2 \%) \text {, } \\
\text { other (no-medical) } 6(7 \%)\end{array}$ & Other (no-medical) $6(15 \%)$, medication $1(2 \%)$ \\
\hline Other treatment & $\begin{array}{l}\text { No treatment } 59(67 \%) \text {, physical therapy } 14(16 \%) \text {, } \\
\text { manual therapy } 6(7 \%) \text {, other } 5(6 \%) \text {, missing } 4(5 \%)\end{array}$ & $\begin{array}{l}\text { No treatment } 38(93 \%) \text {, physical therapy } 6(15 \%) \text {, } \\
\text { manual therapy } 1(2 \%) \text {, other } 1(2 \%) \text {, missing } 4(10 \%)\end{array}$ \\
\hline
\end{tabular}

a Total number of recurrent episodes $(N=37)$ and recurrent episodes lasting longer then 12 weeks $(N=4)$ 
univariate-related to chronicity $(P<0.1)$. Table 3 presents the results of the univariate and the multivariate analyses.

\section{Assessed postures}

'Cohorts' mean 24HS score at baseline was 34.4 (SD 8.2), and at follow-up 1.1 (SD 14.1). All assessed 24HS scores differed significantly between the groups (persistent LBP or not). See also Table 4, where scores are separately presented.

The differences in distribution of 24HS sum-scores at 'baseline' and 'follow-up' are illustrated in Fig. 2. The individual scores were either marked for persistent LBP or not.

A univariate regression analysis was performed to assess the association between changes in 24HS scores (at baseline and follow-up) and the dependent variable persistent LBP. The OR for persistent LBP was 0.96 (95\% C.I. 0.930.99), indicating a protective effect for changes in $24 \mathrm{HS}$ scores.

\section{Discussion}

In our cohort, 35 (40\%) of the patients with LBP recovered fully within 12 weeks and did not experience a recurrent episode within 6 months. This rate of recovery was also observed in comparable primary care studies [27]. The continuous variable age and the dichotomised variable smoking were identified as prognostic factors. Since it was hypothesised that an advanced age is associated with an increased risk of chronic pain (relative risk increased by 1.36 for each 10-year age) [22], this result is noticeable. Still, a similar association was described previously, although not statistically significant [26].

At baseline, all subjects received guideline-based information. This information was summarised in a folder, which the subjects received. It is thinkable that elder subjects were more seriously in their coping behaviour regarding these advises. Possibly the protective effect of advanced age on chronicity could be explained by subjects' coping behaviour. The mean number of GP consultations per person for LBP recorded in this study was 1.2 including the index consult, which is less compared with the 1.6 reported in Great-Britain [17]. Possibly, the strategy described is beneficial in terms of cost effectiveness. However, a controlled study is required to enable a statement regarding the cost effectiveness.

Receiving physical therapy was univariate-associated with chronicity $(P<0.1)$. As suggested in the Dutch Guideline for General Practitioners 'Low Back Pain', physical therapy can be considered for episodes LBP lasting longer than 6 weeks [5]. In this view, receiving physical therapy can be seen as a consequence of the recommendations of the evidence-based guideline, rather then a prognostic factor for chronic LBP.

As risk factor, 24HS scores were strongly associated with the occurrence of LBP [4], but as prognostic factor, subjects' 24HS scores at baseline were not associated with persistent LBP. Changes in all 24HS scores (between baseline and follow-up) were statistically significant. The univariate analysis indicated a significant association between changes in 24HS scores and persistent LBP. The odds ratio for persistent LBP reduced significantly with a factor of 0.96 for every schedule hour the follow-up score changed from the baseline score. Consequently, the greater the subjects' change in baseline-follow-up 24HS score the smaller the odds for persistent LBP. This could indicate that mechanical load of the spine is a modifiable factor in the prognosis of LBP. Whether mechanical loading indeed is a modifiable factor and an effective intervention should be examined in future controlled studies.

Because 24HS score changes were not present at baseline this variable was not regarded a prognostic variable. Therefore, this variable was excluded from the multivariate model.

The classification of low back pain into acute, sub-acute (6-12 weeks), and chronic ( $>12$ weeks) is a simplification of reality, but necessary for scientific studies and useful in clinical practice [30]. To understand the prognostic factors for the development of persistent LBP, we recruited a cohort of subjects with acute LBP in particular without a pervious episode in the past year. By this, we avoided bias [23] due to a mixed cohort of patients with acute low back pain, recent exacerbations and chronic low back pain. We used blinded assessment and performed statistical adjustment for prognostic factors.

Despite being consecutive primary care patients, the population studied cannot be considered representative of the general population of acute low back pain patients. All the subjects sought medical care, which may be related to various socioeconomic factors. The exclusion criteria may have led to an under representation of poorly educated and foreign origin patients. However, the study population represented the source population in primary care.

The data used for the $24 \mathrm{HS}$ were obtained from interviews using retrospective data for subjects' description of 'an average day', and the quality may therefore be questioned. For that reason, the 24HS scores are considered as an indication of the mechanical load.

\section{Conclusion}

Mechanical loading of the spine, quantified with the 24HS, at baseline is not a prognostic factor for chronicity or 


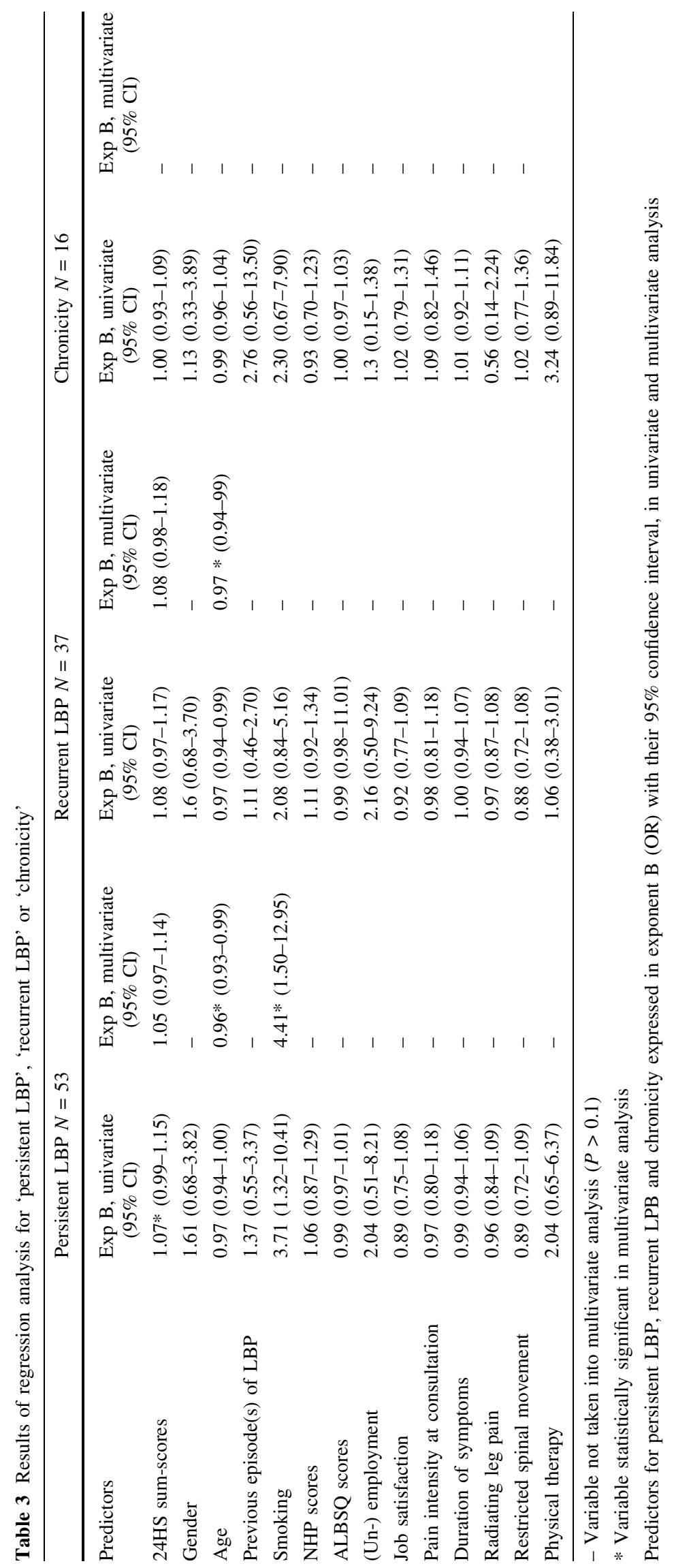


Table 4 24HS Mean sum-scores at baseline and six months follow-up

\begin{tabular}{lllll}
\hline 24HS Sum-score at & Persistent LBP $N=53$ & No-persistent LBP $N=35$ & Mean difference & $P$ \\
\hline Baseline (SD) & $36.1(3.5)$ & $32.6(11.8)$ & 3.5 & 11.2 \\
Follow-up (SD) & $5.4(14.2)$ & $-5.8(11)$ & 7.6 & $0.04 *$ \\
Change (SD) & $30.7(13.7)$ & $38.3(14.2)$ & $0.01 *$ \\
\hline
\end{tabular}

Mean difference statistically significant

Fig. 2 Distribution of subjects' 24HS sum-scores at baseline and follow-up
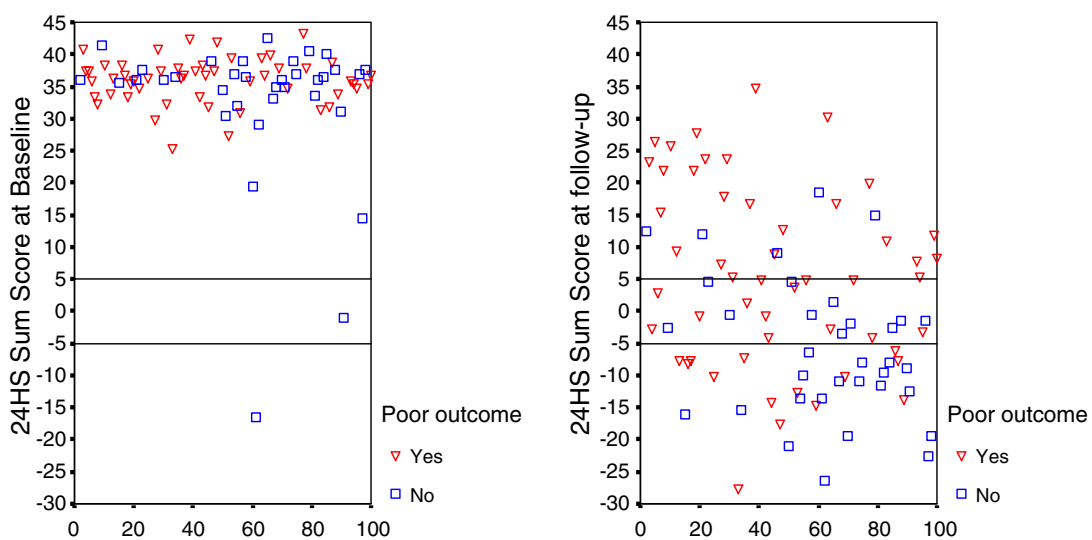

recurrent episodes. Possibly modification of spinal mechanical loading in terms of 24HS scores might be beneficial for secondary prevention in patients with acute LBP.

Acknowledgments The authors highly appreciate the help of Mariska Maris, research assistant.

\section{References}

1. Altman DG (1980) Statistics and ethics in medical research: III. How large a sample. Br Med J 281:1336-1338

2. Altman DG (1997) Relation between several variables. In: Altman DG (ed) Practical statistics for medical research. Chapman \& Hall/CRC, Boca Raton pp 325-361

3. Bakker EWP, Koning JCMF, Verhagen AP, Koes BW (2003) Interobserver reliability of the 24-hour schedule in patients with low back pain. JMPT 26(4):226-232

4. Bakker EWP, Verhagen AP, Lucas C, Koning JCMF, Haan de RJ, Koes BW (2006) Daily spinal mechanical loading as a risk factor for acute non-specific low back pain. Eur Spine J (epub ahead of print)

5. Chavannes AW, Mens JMA, Koes BW, Lubbers WJ, Ostelo R, Spinnewijn WEM, Kolnaar BGM (2005) NHG-standaard lage rugpijn. Huisarts Wet 48(3):113-123

6. Croft PR, Macfarlane GJ, Papageorgiou AC, Thomas E, Silman AJ (1998) Outcome of low back pain in general practice: a prospective study. BMJ 316(7141):1356-1359

7. Dionne CE, Koepsell TD, Von Korff M, Deyo RA, Barlow WE, Checkoway H (1997) Predicting long-term functional limitations among back pain patients in primary care settings. J Clin Epidemiol 50(1):31-43

8. Dunn KM, Croft PR (2004) Epidemiology and natural history of low back pain. Eura Medicophys 40(1):9-13
9. Erdman RA, Passchier J, Kooijman M, Stronks DL (1993) The Dutch version of the Nottingham Health Profile: investigations of psychometric aspects. Psychol Rep 72(3 Pt 1):1027-1035

10. Faas A, Chavannes AW, Koes BW, Hoogen JMM van den, Mens JMA, Smeele LJM (1996) NHG-standaard lage rugpijn. Huisarts Wet 39:18-31

11. Frymoyer JW (1988) Back pain and sciatica. N Engl J Med 318:291-300

12. Hoogen van den HJ, Koes BW, Deville W, van Eijk JT, Bouter LM (1997) The prognosis of low back pain in general practice. Spine 1 22(13):1515-1521

13. Jeaschke R, Singer J, Guyatt GH (1990) A comparison of seven-point and visual analogue scales. Control Clin Trials 11:4351

14. Koes BW, van Tulder MW, Ostelo R, Kim Burton A, Waddell G (2001) Clinical guidelines for the management of low back pain in primary care: an international comparison. Spine 26(22):25042513

15. Maniadakis N, Gray A (2000) The economic burden of back pain in the UK. Pain 84(1):95-103

16. Nachemson A (1975) Towards a better understanding of lowback pain: a review of the mechanics of the lumbar disc. Rheumatol Rehabil 14(3):129-143

17. OPCS (1994) Office of Population Censuses and Surveys. Monitor MB5 94/1 Morbidity Statistics from General Practice 1991/2 (MSGP4). HMSO, London

18. Papageorgiou AC, Macfarlane GJ, Thomas E, Croft PR, Jayson MIV, Silman AJ (1997) Psychosocial factors in the work place-do they predict new episodes of low back pain? Spine 22:1137-1142

19. Pengel LHM, Herbert RD, Maher CG, Refshauge KM (2003) Acute low back pain: systematic review of its prognosis. BMJ 327(7410):323

20. Pincus T, Burton AK, Vogel S, Field AP (2002) A systematic review of psychological factors as predictors of chronicity/disability in prospective cohorts of low back pain. Spine 27:E109E120 
21. Reis S, Hermoni D, Borkan JM, Biderman A, Tabenkin C, Porat A (1999) A new look at low back complaints in primary care: a RAMBAM Israeli Family Practice Research Network study. J Fam Pract 48:299-303

22. Rossignol M, Suissa S, Abenhaim L (1988) Working disability due to occupational back pain: three years follow-up of 2300 compensated workers in Quebec. J Occup Med 30:502505

23. Sackett DL, Haynes RB, Guyatt GH, Tugwell P (1991) Clinical epidemiology, a basic science for clinical medicine. Little, Brown, Boston

24. Sato K, Kikuchi S, Yonezawa T (1999) In vivo intradiscal pressure measurement in healthy individuals and in patients with ongoing back problems. Spine 24(23):2468-2474

25. Seferlis T, Nemeth G, Carlsson AM (2000) Prediction of functional disability, recurrences, and chronicity after 1 year in 180 patients who required sick leave for acute low-back pain. J Spinal Disord 13:470-477
26. Schiottz-Christensen B, Nielsen GL, Hansen VK, Schodt T, Sorensen HT, Olesen F (1999) Long-term prognosis of acute low back pain in patients seen in general practice: a 1-year prospective follow-up study. Fam Pract 16:223-232

27. Thomas E, Silman AJ, Croft PR, Papageorgiou AC, Jayson MI, Macfarlane GJ (1999) Predicting who develops chronic low back pain in primary care: a prospective study. BMJ 19 318(7199):1662-1667

28. Vlaeyen JWS, Heuts PHTG (2000) Gedragsgeoriënteerde behandeling bij lage rugpijn. Bohn Stafleu Van Loghum, Houten/ Diegem

29. Waddell G (1987) A new clinical model for the treatment of low back pain. Spine 12:632-644

30. Waddell G (2004) The back pain revolution, 2nd edn. Churchill Livingstone, London

31. Walker BF (2000) The prevalence of low back pain: a systematic review of the literature from 1966 to 1998. J Spinal Disord 13(3):205-217 